This is the peer reviewed version of the following article:

Kosanović, D., Živojinović, J., Obradović, N., Pavlović, V.P., Pavlović, V.B., Peleš, A., Ristić, M.M., 2014. The influence of mechanical activation on the electrical properties of $\mathrm{Ba} 0.77 \mathrm{Sr} 0.23 \mathrm{TiO} 3$ ceramics. Ceramics International 40, 11883-11888.

https://doi.org/10.1016/j.ceramint.2014.04.023

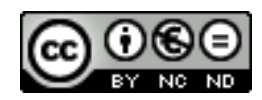

This work is licensed under a Creative Commons - Attribution-Noncommercial-No Derivative Works 3.0 Serbia. 


\title{
The influence of mechanical activation on the electrical properties of $\mathrm{Ba}_{0.77} \mathrm{Sr}_{0.23} \mathrm{TiO}_{3}$ ceramics
}

\author{
D. Kosanović ${ }^{a,{ }^{*}}$, J. Živojinovića ${ }^{a}$ N. Obradovića ${ }^{a}$, V. P. Pavlović ${ }^{b}$, V. B. Pavlovića \\ A. Peleša ${ }^{\mathrm{a}}$ M. M. Ristićc \\ ${ }^{\text {a }}$ Institute of Technical Sciences of the Serbian Academy of Sciences and Arts, \\ Knez Mihailova 35/IV, 11000 Belgrade, Serbia \\ ${ }^{\mathrm{b}}$ Faculty of Mechanical Engineering, University of Belgrade, Belgrade, Serbia \\ ${ }^{c}$ Serbian Academy of Sciences and Arts, Knez Mihailova 35, 11000 Belgrade, Serbia
}

\begin{abstract}
Ferroelectric barium strontium titanate $\left(\mathrm{Ba}_{0.77} \mathrm{Sr}_{0.23} \mathrm{TiO}_{3}\right)$, BST, was prepared by solidstate reactions using as the starting compounds the powders of barium carbonate $\left(\mathrm{BaCO}_{3}\right)$, strontium carbonate $\left(\mathrm{SrCO}_{3}\right)$ and titanium dioxide $\left(\mathrm{TiO}_{2}\right.$-anatase). Non-activated mixtures and mixtures mechanically activated in a high-energy planetary ball mill $(0,5,10,20,40,80$ and 120 minutes) were sintered at 1100, 1200, 1300 and $1400{ }^{\circ} \mathrm{C}$ for 2 hours in air atmosphere. Defects and the effect of the beginning of the sintering process on the microstructure were investigated by scanning electron microscopy (SEM). Electrical measurements (loss tangent and resistivity as the function of frequency $\left.\mathrm{X}_{\mathrm{C}}=\mathrm{f}(\log v)\right)$ were performed for ceramics sintered at $1400{ }^{\circ} \mathrm{C}$ for two hours. It has been found that mechanical activation can reduce the sintering temperature by around $100{ }^{\circ} \mathrm{C}$, which leads to significant energy savings.
\end{abstract}

Key words: electrical measurements, mechanical activation, barium-strontium-titanate

\footnotetext{
${ }^{*}$ Corresponding author:

Tel: +381-11-2027284

Fax: $+381-11-2185263$

E-mail: darko.kosanovic@itn.sanu.ac.rs (D. Kosanović)

kosanovic.darko@gmail.com
} 


\section{Introduction}

Ferroelectric ceramics, ferroelectrics, are usually alkaline earth metal titanates: $\mathrm{BaTiO}_{3}, \mathrm{SrTiO}_{3}, \mathrm{CaTiO}_{3},(\mathrm{BaSr}) \mathrm{TiO}_{3}, \mathrm{Ba}(\mathrm{ZrTi}) \mathrm{O}_{3}$ [1]. Ceramic capacitors based on titanate have very high capacity and small size which enable the miniaturization of electronic devices. Among the mentioned compounds, $\left(\mathrm{BaTiO}_{3}\right)_{0.65}\left(\mathrm{SrTiO}_{3}\right)_{0.35}$ has the best properties, due to the large $\varepsilon_{\mathrm{r}}$ and the corresponding $\operatorname{tg} \delta$. The disadvantages include large and highly non-linearly changing capacitance with temperature change $([\Delta \mathrm{C} / \mathrm{C}] / \Delta \mathrm{t})$, in the operating temperature range $\left(\sim 55-125^{\circ} \mathrm{C}\right)[2]$.

Barium strontium titanate, $\mathrm{Ba}_{1-\mathrm{x}} \mathrm{Sr}_{\mathrm{x}} \mathrm{TiO}_{3}(\mathrm{BST})$ is a ferroelectric material with potential application in microwave devices. BST is a continuous solid solution with a tetragonal structure; it belongs to the family of $\left(\mathrm{ABO}_{3}\right)$ perovskites and it is composed of titanate, barium titanate $\left(\mathrm{BaTiO}_{3}\right)$ and strontium titanate $\left(\mathrm{SrTiO}_{3}\right) . \mathrm{BaTiO}_{3}\left(\mathrm{~T}_{\mathrm{C}}=393 \mathrm{~K}\right)$ is a prototype ferroelectric which undergoes a sequence of crystal structure transitions as it switches from the ferroelectric to the paraelectric phase [3]. $\mathrm{SrTiO}_{3}$ is an incipient ferroelectric i.e. it exhibits quantum ferroelectricity which means that it undergoes phase transition at very low temperatures $\left(\mathrm{T}_{\mathrm{C}}=105 \mathrm{~K}\right)$, the quantum effect prevents complete transition to paraelectric phase [4-6].

BST is being widely investigated as a suitable dielectric material for a variety of applications including tunable RF and microwave circuits, dynamic random access memories (DRAM), bypass capacitors, and non-volatile memories [7]. Thin-film BST has several properties that make these applications possible. Most importantly, the BST films show a field-dependent permittivity. When BST is applied as a capacitor, the dielectric constant changes in a non-linear function. The nonlinearity of dielectric properties with respect to an applied dc voltage makes BST attractive for tunable microwave devices such as varistors, filters, voltage-controlled oscillators (VCO), delay lines and phase shifters [8].

The aim of this study is to investigate the influence of mechanical activation and the sintering regime on the structure and electrical properties of BST ceramics. Based on a detailed analysis of temperature dependence, loss tangent of the angle, and the influence of mechanical activation on the change of frequency characteristics, optimum technological parameters for obtaining $\mathrm{Ba}_{0.77} \mathrm{Sr}_{0.23} \mathrm{TiO}_{3}$ ceramics with improved electrical characteristics will be defined. 


\section{Experimental procedure}

Mixtures of $\mathrm{BaCO}_{3}$ (99.8 \% p.a. Aldrich), $\mathrm{SrCO}_{3}\left(99.8 \%\right.$ p.a. Aldrich) and $\mathrm{TiO}_{2}$ (99.99 \% p.a. Aldrich) powders in the molar range $\mathrm{BaCO}_{3}: \mathrm{SrCO}_{3}: \mathrm{TiO}_{2}=0.77: 0.23: 1$ were mechanically activated in a high-energy Planetary ball mill (Retsch, PM 400). The process of milling was performed for 0 to $120(0,5,10,20,40,80$ and 120) minutes in air atmosphere. Initial samples were milled in $500 \mathrm{~cm}^{3}$ zirconium oxide beakers together with balls of $10 \mathrm{~mm}$ in diameter (the ratio of powder and balls was 1:20). After milling, the powders were dried and calcined at a temperature of $800{ }^{\circ} \mathrm{C}$, for four hours inside a chamber furnace.

The samples of activated and then calcined BST powders were pressed at $4 \mathrm{t} / \mathrm{cm}^{2}(392$ $\mathrm{MPa}$ ). They were sintered in air atmosphere and in a lab chamber furnace (Electron) whose maximum temperature is $1600{ }^{\circ} \mathrm{C}$. The samples were placed into the furnace and sintered at temperatures of $1100,1200,1300$ and $1400{ }^{\circ} \mathrm{C}$ for $2 \mathrm{~h}$. The heating rate was $10{ }^{\circ} \mathrm{C} / \mathrm{min}$, and when the furnace reached the temperatures of $1100,1200,1300$ and $1400{ }^{\circ} \mathrm{C}$, the pressed samples were sintered isothermally for $2 \mathrm{~h}$. The morphology of sintered BST was analyzed using a scanning electron microscope (SEM, JSM-6390 LV JEOL, 25kV).

Roentgenograms of the sintered samples were obtained on a Philips PW 1050 diffractometer, using the $\lambda \mathrm{CuK} \alpha$ owl radiation and the "step scan" mode with increments of $0.05^{\circ}$. The measurement of the dielectric loss tangent and the values of the real (R) and imaginary $\left(\mathrm{X}_{\mathrm{C}}\right)$ component of the complex electrical impedance of the sintered samples were carried out on the device HIOKI 3532-50 LCR HiTESTER, at the operating frequency of 1 $\mathrm{kHz}$ and $10 \mathrm{kHz}$. The sample preparation involved the application of platinum paste on both sides of the sintered samples, which were then heated for 30 minutes at $150{ }^{\circ} \mathrm{C}$ with the intent of curing the paste and improving conductivity.

\section{Results and discussion}

The greatest changes in the density of the samples occur at 1100 and $1200{ }^{\circ} \mathrm{C}$ for samples activated for five minutes, while the effect of a prolonged milling time for 10 and 20 minutes are negligible at these sintering temperatures. Small changes in the density at lower sintering temperatures clearly indicate that the final stage of the sintering process occurs at higher sintering temperatures. 
Table 1 shows densities of BST-S samples sintered at the following temperatures: $1100,1200,1300$ and $1400{ }^{\circ} \mathrm{C}$ for two hours.

Table 1. Sample densities, $\rho_{\mathrm{s}}\left(\mathrm{g} / \mathrm{cm}^{3}\right)$ of samples sintered isothermally at temperatures of $1100,1200,1300$ and $1400{ }^{\circ} \mathrm{C}$ for $2 \mathrm{~h}$.

\begin{tabular}{|c|c|c|c|c|}
\hline Sample & $\mathbf{1 1 0 0}{ }^{\mathbf{0}} \mathbf{C}, \mathbf{2 h}$ & $\mathbf{1 2 0 0}{ }^{\mathbf{0}} \mathbf{C}, \mathbf{2 h}$ & $\mathbf{1 3 0 0}{ }^{\mathbf{}} \mathbf{C}, \mathbf{2 h}$ & $\mathbf{1 4 0 0}{ }^{\mathbf{}} \mathbf{C}, \mathbf{2 h}$ \\
\hline BST-0 & 3.367 & 3.750 & 4.338 & 4.518 \\
\hline BST-5 & 3.643 & 3.939 & 4.393 & 4.606 \\
\hline BST-10 & 3.671 & 3.982 & 4.409 & 4.654 \\
\hline BST-20 & 3.680 & 3.972 & 4.421 & 4.688 \\
\hline BST-40 & 3.934 & 4.098 & 4.444 & 4.815 \\
\hline BST-80 & 4.118 & 4.199 & 4.526 & 4.941 \\
\hline BST-120 & 4.204 & 4.352 & 4.633 & 5.030 \\
\hline
\end{tabular}

Analysis of the results of isothermal sintering (Table 1) shows that the best effect is achieved by mechanical activation for 120 minutes at the sintering temperature of $1400{ }^{\circ} \mathrm{C}$.

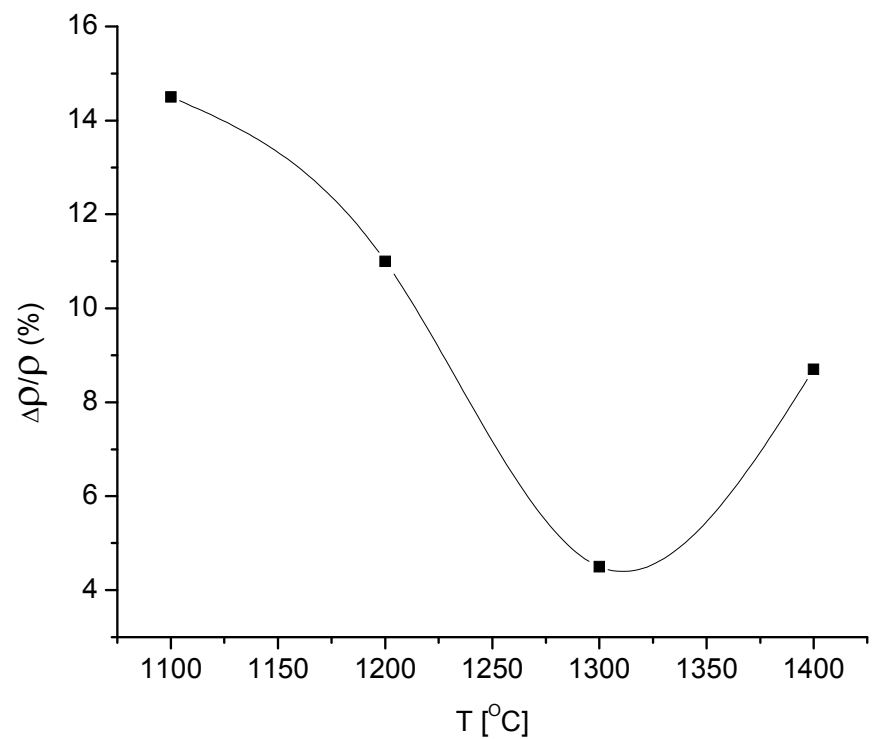

Fig. 1. Density differences in non-activated samples and the sample activated for 120 minutes, both sintered, as the function of the sintering temperature. 
The analysis of the dependence of density differences in activated and non-activated samples shows that the minimal effect of milling is observed at $1300{ }^{\circ} \mathrm{C}$, whereas the maximum effect can be seen in the samples sintered at $1100{ }^{\circ} \mathrm{C}$. Accordingly, energy savings are achieved using mechanical activation, which also results in good technical properties of ceramics at lower sintering temperatures.

Based on our previous results, the diffraction patterns of non-activated and mechanically activated BST isothermally sintered at $1400{ }^{\circ} \mathrm{C}$ for two hours indicate that the phase composition of the sintered samples has four phases [9]. Well crystallized phase $\mathrm{Ba}_{0.77} \mathrm{Sr}_{0.23} \mathrm{TiO}_{3}$ shows sharp and intense peaks and phases, such as witherite $\left(\mathrm{BaCO}_{3}\right)$, strontium carbonate $\left(\mathrm{SrCO}_{3}\right)$ and anatase $\left(\mathrm{TiO}_{2}\right)$ which occur in low concentrations. The peaks of the milled and sintered samples are reduced, which means that there is a narrowing of peaks, indicating an improved crystallinity of the samples (Fig. 2). Having in mind that the increase in the sintering temperature stabilizes the crystal structure due to the recrystallization process, it may be concluded that all of the above-mentioned facts suggest that the formation of a solid solution, the composition of which is $\mathrm{Ba}_{0.77} \mathrm{Sr}_{0.23} \mathrm{TiO}_{3}$, has actually occurred in the system.

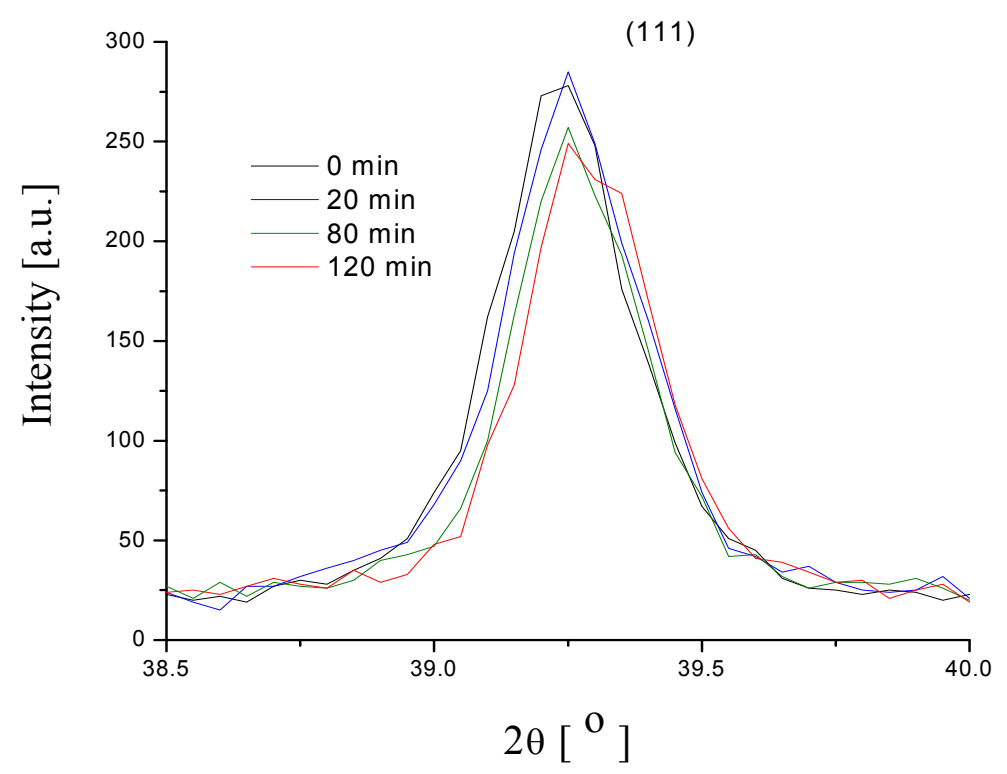

Fig. 2. Influence of the activation time on the full width at the half-maximum of diffraction lines (111) on diffractogram of sintered BST ceramics.

The analysis of the evolution of microstructural constituents during sintering, performed by scanning electron microscopy, confirms the previously presented conclusions. Based on this analysis, it has been found that an increased temperature and extended sintering 
time result in the related processes of grain growth and pore size reduction. Micrographs of the samples of BST-S-0, BST-S-20, BST-S-80 and BST-S-120 sintered at $1400{ }^{\circ} \mathrm{C}$ for two hors are shown in Fig. 3.

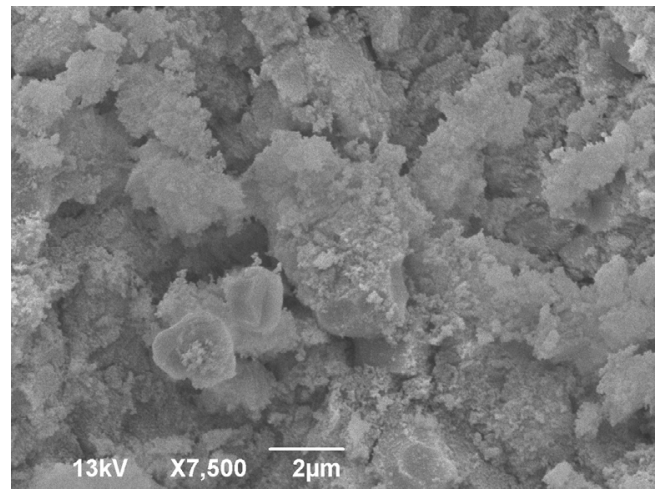

(a)
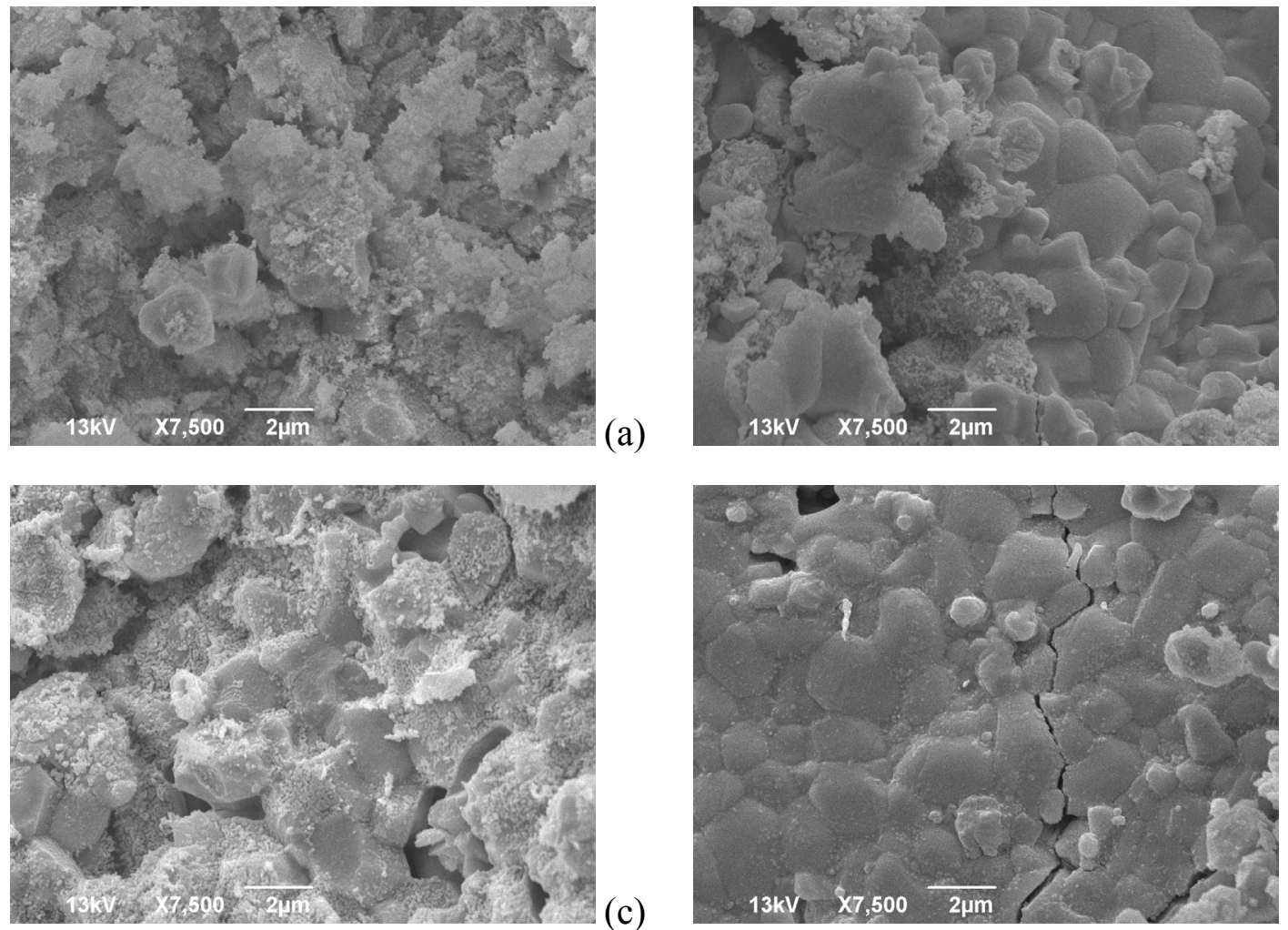

(d)

Fig. 3. Scanning electron micrographs of samples (a) BST-S-0, (b) BST-S-20, (c) BST-S-80 and (d) BST-S-120 sintered non-isothermally at $1400{ }^{\circ} \mathrm{C}$ and isothermally for two hours.

The SEM micrograph of the starting powder shows a large open porosity of grains of different sizes. Fig. 3a (BST-S-0) indicates the presence of larger, well-formed grains of barium strontium titanate (as one phase) and smaller grains (as the second phase). Also, in the non-activated samples, a non-homogeneous porous microstructure is observed, which is prevailed by the polygonal grain shape and the presence of the so-called texture open porosity, with pores of an irregular shape. In the sample was mechanically activated for 20 minutes, uneven densification and grain growth (barium strontium titanate) have been observed (Fig. 3b). The micrograph shows the presence of a second phase (smaller particles), but they are evenly distributed. The SEM micrograph of the sample mechanically activated for 20 minutes shows an increased mass transport. It is caused by the higher surface activity of grain boundaries and leads to their structural reinforcement, resulting in the appearance of fracture patterns. The micrographs in Figs. $3 \mathrm{c}$ and $3 \mathrm{~d}$ show that the increase of the activation 
time results in a growth of a new phase, along with the size reduction of the second phase and the reinforcement of the boundaries between grains.

Finally, the formation of the most compact structure of a polygonal shape, mediumsized with a slight presence of an unreacted second phase, has been observed. Also, there is a dominant presence of closed porosity in which spherical pores were identified, and this phenomenon shows that the system entered into the final sintering stage.

The influence of temperature on the dielectric loss in the samples $\mathrm{Ba}_{0.77} \mathrm{Sr}_{0.23} \mathrm{TiO}_{3}$ (BST-S) sintered at $1400{ }^{\circ} \mathrm{C}$ during two hours was considered at frequencies of $1 \mathrm{kHz}$ and 10 $\mathrm{kHz}$.
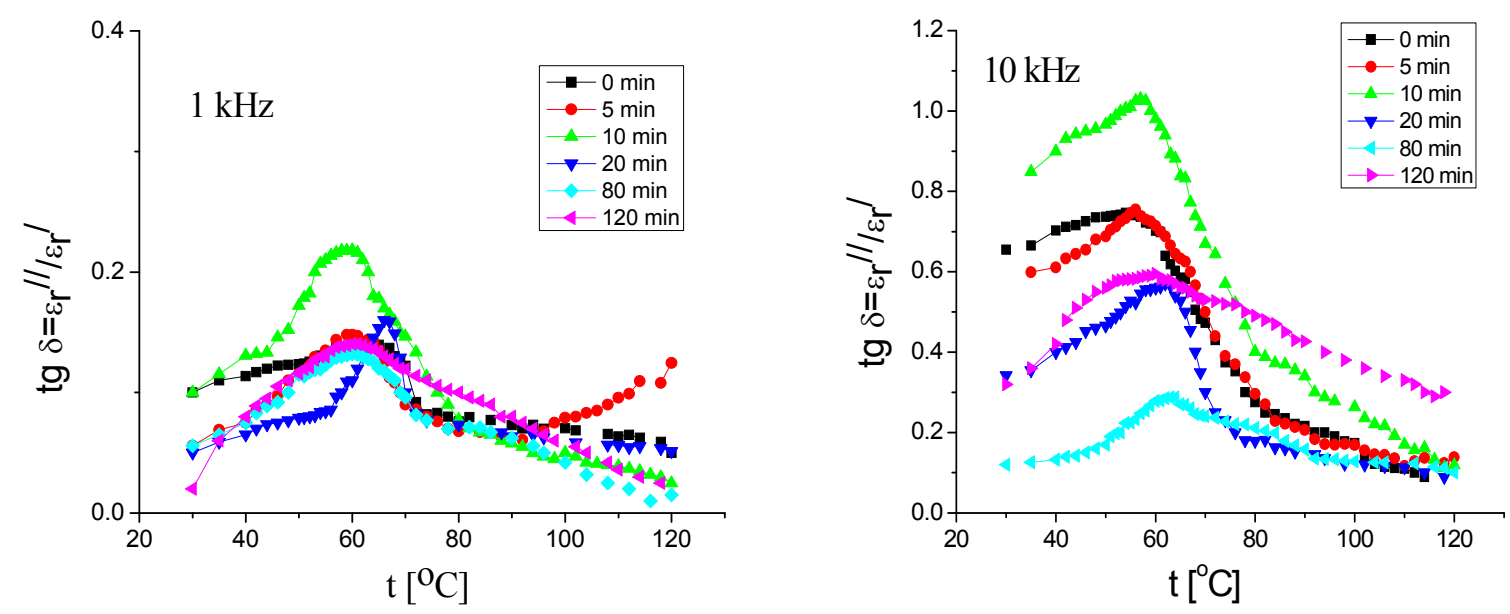

Fig. 4. Influence of the activation time on the temperature dependence of the dielectric loss in BST-S sintered samples at frequencies of $1 \mathrm{kHz}$ and $10 \mathrm{kHz}$ (system uses a dielectric loss tangent of the angle calculated from the ratio of $\varepsilon_{r}^{\prime}$ and $\left.\varepsilon_{r}^{\prime \prime}\right)$.

Based on the experimental results shown in Fig. 4, it can be concluded that $\operatorname{tg} \delta$ increases with an increased sintering temperature (that the peaks were more pronounced). It is observed that in all sintered samples with prolonged activation times the first decline occurs in the value of the Curie-temperature, and then possibly decline in the value $\operatorname{tg} \delta$. 


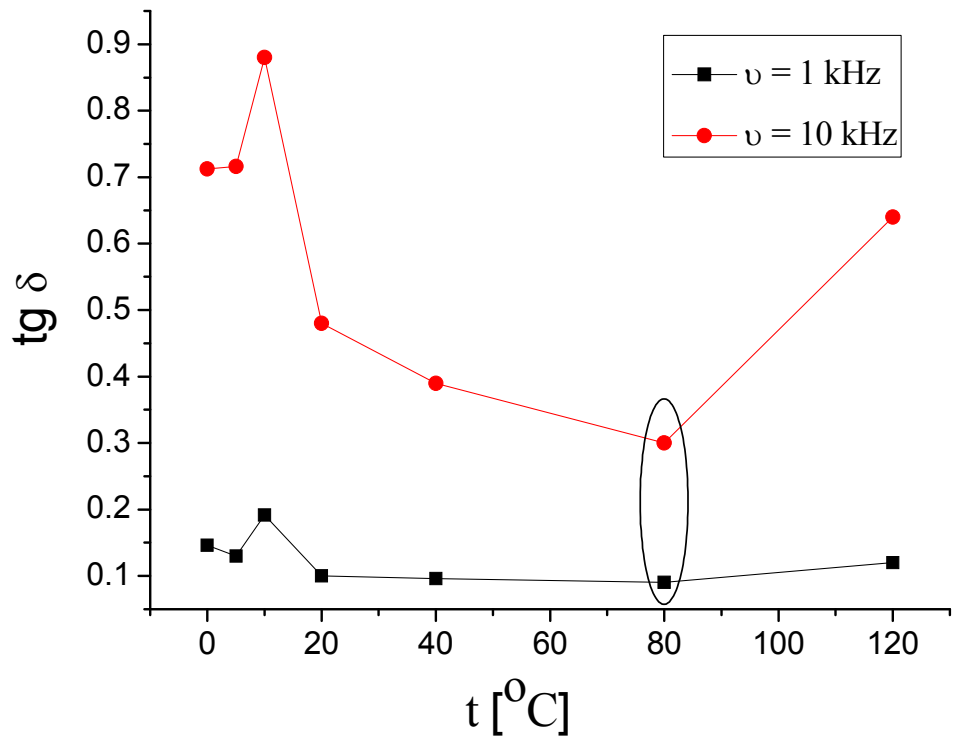

Fig. 5. Influence of the activation time on the temperature dependence of the dielectric loss in BST-S sintered samples at frequencies of $1 \mathrm{kHz}$ and $10 \mathrm{kHz}$.

Based on the analysis of the results shown in Fig. 5. it can be concluded that the optimal duration of the mechanical activation of the starting powders is 80 minutes. The samples of the powder sintered at $1400{ }^{\circ} \mathrm{C}$ for $2 \mathrm{~h}$ have about $36 \%$ lower dielectric loss at the frequency of $1 \mathrm{kHz}$ and about $57 \%$ at the frequency of $10 \mathrm{kHz}$ than the samples obtained from the initial non-activated powder sintered under the same conditions. The dependence graphs $\mathrm{X}_{\mathrm{C}}=\mathrm{f}(\log v)$ for the non-activated samples and those mechanically activated for 5, 10, 20, 80 and 120 minutes at temperatures from 310 to $410{ }^{\circ} \mathrm{C}$ are shown in Figs. 6-8. For the experimentally observed dependence graphs $X_{C}=f(\log v)$ for the non-activated samples and those mechanically activated for 5, 10, 20, 80 and 120 minutes in the paraelectrics one or two peaks appear, depending on the observed temperature and activation powders. For the temperatures of 310 and $360{ }^{\circ} \mathrm{C}$, two peaks are observed. The first, more intense, is located in the lower frequencies and the corresponding grain boundary, and its frequency corresponds to the frequency at the top of the large semicircle in the $Z^{*}$ plane. The second, less pronounced peak at higher frequencies, corresponds to the grain (Figs. 6-8).
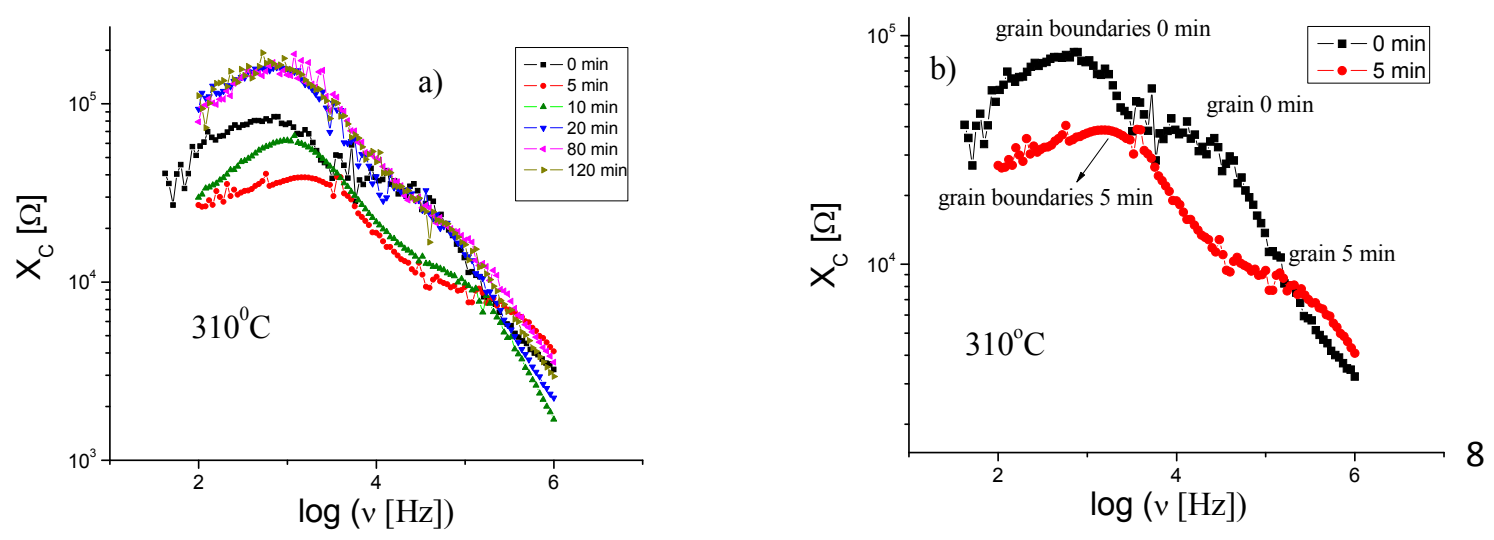


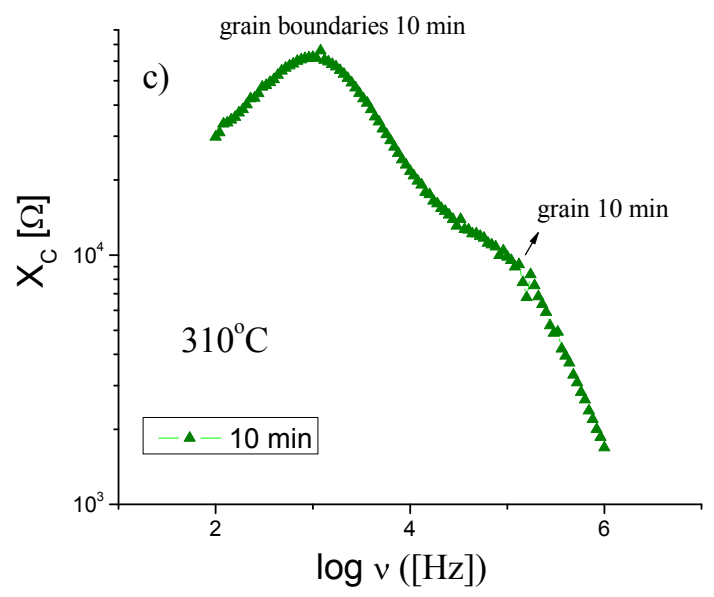

Fig. 6. Influence of activation time on the frequency dependence of reactance $X_{C}=f(\log v)$ at a temperature of $310{ }^{\circ} \mathrm{C}$.

The activated samples heated at $310^{\circ} \mathrm{C}$ show a decrease in the intensity of both peaks in the frequency dependence of reactance graph $\mathrm{X}_{\mathrm{C}}=\mathrm{f}(\log v)$ and the change of the position of their maxima, while the change of the intensity and position of peaks reflect the properties of the grain boundaries (Fig. 6.). In the samples obtained from the powder activated for five minutes, the peak corresponding to the grain boundary decreases sharply, spreads and shifts to higher frequencies (Fig. 6 a). As we move to higher frequencies, the peak corresponding to the grain also shifts, but to a considerably lesser degree; the peaks corresponding to the grain and grain boundary become closer only in terms of intensity but not in terms of position (activated samples 20, 80 and 120 minutes); therefore no superposition occurs.

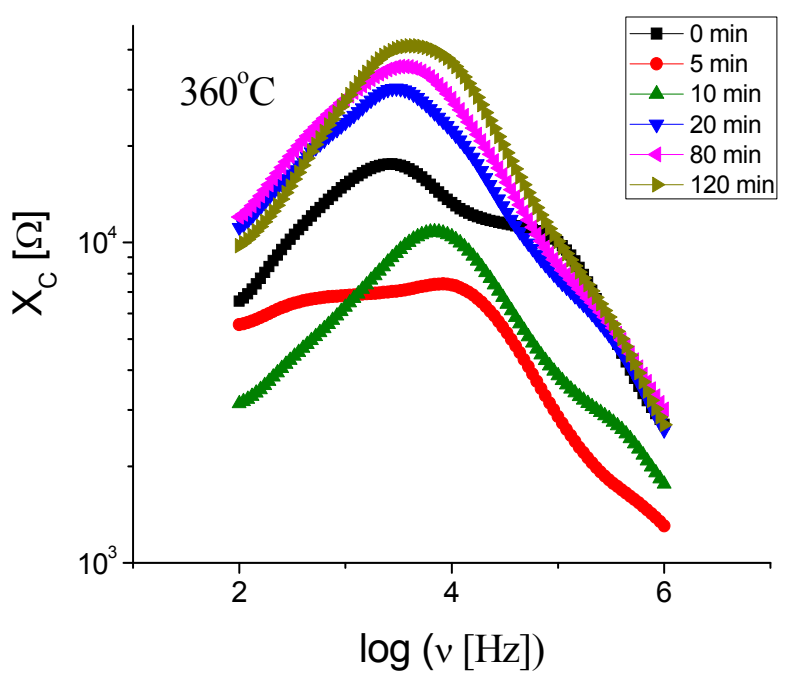


Fig. 7. Influence of activation time on the frequency dependence of reactance $X_{C}=f(\log v)$ at a temperature of $360{ }^{\circ} \mathrm{C}$.

In Fig. 7. the influence of activation time on the frequency dependence of reactance $\mathrm{X}_{\mathrm{C}}=\mathrm{f}(\log v)$ at a temperature of $360{ }^{\circ} \mathrm{C}$ is shown. For the samples activated for five minutes the reduction in the intensity of both peaks, as well as the change in the position of their maxima, have been compared to the non-activated sample. The samples that were activated for more than five minutes $(10,20,80$ and 120 minutes) show a significant increase of the intensity peaks and their position, compared to the non-activated sample. The change of peak positions reflects the properties of grains and grain boundaries; they are shifted to lower frequencies. The changes in the peak intensities caused by activation, lead to the partial overlapping of the activation patterns of the samples activated for 20, 80 and 120 minutes. In the samples activated for 10 minutes, one peak is observed, and it originates from the influence of agglomerates' boundaries.

In Fig. 8, the influence of the activation time on the frequency dependence of reactance $\mathrm{X}_{\mathrm{C}}=\mathrm{f}(\log v)$ at a temperature of $410{ }^{\circ} \mathrm{C}$ is shown. In the samples activated for 10 minutes, a decrease in peak intensity and a change in the position of the maximum have been observed; at the same time mechanical activation largely brings about a change in the intensity and position of the peak which reflects the properties of grain boundaries. For the samples obtained from the powder activated for 10 minutes, the peak corresponding to grain boundary decreases sharply, spreads and shifts to higher frequencies (Fig. 8.).

The 10-munute activation results in a rapid growth and reversed directions of peak shifts, which represent the grain boundaries. This is in line with the changes in the microstructure of the samples that were previously discussed. 


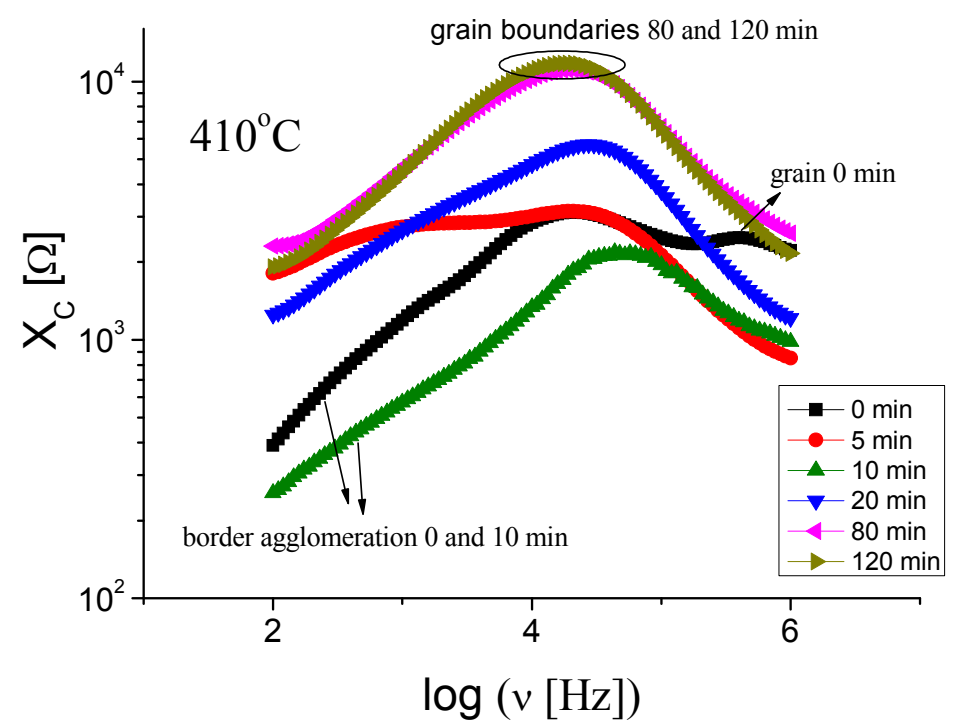

Fig. 8. Influence of activation time dependence: $X_{C}=f(\log v)$ at a temperature of $410{ }^{\circ} \mathrm{C}$.

\section{Conclusion}

In this article, the influence of mechanical activation on the electrical properties of $\mathrm{Ba}_{0.77} \mathrm{Sr}_{0.23} \mathrm{TiO}_{3}$ ceramics has been investigated.

- Based on the measurement of the relative density of the sintered (BST-S) it has been discovered that the greatest change in density occurs in the powders mechanically activated for up to 20 minutes and sintered at $1100{ }^{\circ} \mathrm{C}$ and $1200{ }^{\circ} \mathrm{C}$ for two hours.

- It was found that density of BST-S samples increases with temperature and the sintering time.

- Also, the mechanical activation of the starting powder for 120 minutes can reduce the sintering temperature by around $100{ }^{\circ} \mathrm{C}$, which leads to significant energy savings.

- As far as the dielectric loss is concerned, it has been found that the optimal duration of the mechanical activation of the starting powders is 80 minutes. The samples of the powder sintered at $1400{ }^{\circ} \mathrm{C}$ for $2 \mathrm{~h}$ have about $36 \%$ lower dielectric loss at a frequency of $1 \mathrm{kHz}$ and about $57 \%$ at a frequency of $10 \mathrm{kHz}$ than the samples obtained from the initial non-activated powder sintering under the same conditions.

- By studying the electrical properties of the BST-S sintered samples obtained from the nonactivated powder heated at different temperatures $\left(310,360\right.$, and $\left.410{ }^{\circ} \mathrm{C}\right)$ it has been found 
that with increasing temperatures of the sample both active and reactive components of impedance decrease.

With the increase in temperature the relative ratio of the contribution of the grain and grain boundary resistance alters in favour of the grain boundary.

\section{Acknowledgements}

These study was carried out within the framework of the project OI 172057, funded by the Ministry of Education, Science and Technological Development of the Republic of Serbia and Project F/198, funded by the Serbian Academy of Sciences and Arts.

\section{References}

[1] Acikel, B. "High performance barium strontium titanate varactor technology for low cost circuit applications: A dissertation submitted in partial satisfaction of the requirements for the degree of Doctor of Philosophy in Electrical and Computer Engineering." University of California, Santa Barbara, 2002.

[2] Rabe, K. M., Ch. H. Ahn, J.-M. Triscone, eds. Physics of ferroelectrics: A modern perspective. 1st ed. Berlin, Heidelberg: Springer, 2007.

[3] Tsymbal, E. Y. Dielectric properties of insulators, In PHYSICS 927: Introduction to Solid-State Physics: Practice Exams, Lecture Notes, Textbooks, Study Guides and Study Materials. Lincoln: University of Nebraska, s. a.

[4] K Morito, K., Y. Iwazaki, T. Suzuki, M. Fujimoto, Electric field induced piezoelectric resonance in the micrometer to millimeter waveband in a thin film $\mathrm{SrTiO}_{3}$ capacitor, Journal of Applied Physics 94, no. 8 (2003) 5199.

[5] Mueller, V., H. Beige, H.-P. Abicht. Non-Debye dielectric dispersion of barium titanate stannate in the relaxor and diffuse phase-transition state, Applied Physics Letters 84, no. 8 (2004) 1341.

[6] Смоленский, Г. А., В. А. Исупов, Сегнетоэлектрические свойства твердых растворов станната бария в титанате бария, Журнал технической физики 24 (1954) 1375-1386.

[7] Rabe, K. M., Ch. H. Ahn, J.-M. Triscone, eds. Physics of ferroelectrics: A modern perspective. 1st ed. Berlin, Heidelberg: Springer, (2007) 69-116. 
[8] Thomas, R., V. K. Varadan, S. Komarneni, D. C. Dube, Diffuse phase transitions, electrical conduction, and low temperature dielectric properties of sol-gel derived ferroelectric barium titanate thin films, Journal of Applied Physics 90, no. 3 (2001) 1480.

[9] D. Kosanović, N. Obradović, J. Živojinović, A. Maričić, V. P. Pavlović, V. B. Pavlović, M. M. Ristić, The Influence of Mechanical Activation on Sintering Process of $\mathrm{BaCO}_{3}-\mathrm{SrCO}_{3}$ $\mathrm{TiO}_{2}$ System, Science of Sintering, Vol. 44(3) (2012) 47-55. 